\title{
Evaluation of Hybrid and OPV Maize Varieties for Grain Yield and Agronomic Attributes under Farmer's Field Conditions at Dukuchhap
}

\author{
Min N. Paudel
}

Outreach Research Division, NARC, Khumaltar, Lalitpur, Nepal <mnpaudel@yahoo.com>

\begin{abstract}
Field experiments were conducted during two consecutive years 2006 and 2007 in full season of maize (May-Sep) at Dukuchhap, Lalitpur to find out impact of growing hybrid and OPV maize in different rows combinations with respect to their pure stands in same environment of growing and to sort out non-lodging maize varieties. The experiments consisted of an open pollinated variety (OPV) 'Deuti' and hybrid 'Gaurab' in different row combinations $(50 \%$ hybrid $+50 \%$ OPV, $75 \%$ hybrid $+25 \%$ OPV , 75\% OPV $+25 \%$ hybrid plus their pure stands). The results showed that Gaurab (yellow, flint type) and Deuti (white, semi- flint type, selected from CIMMYT's material ZM 621) did not vary significantly in grain yield and yield components. There was no effect of mixed row culture between the OPV and hybrid for grain yield and yield attributes. A bivariate correlation coefficient between agronomic traits and ear traits indicated that there was a positive relation among these traits. However, a positive and highly significant $\left(\mathrm{r}=0.766^{* *}\right)$ relationship between ear fill and ear length was observed while a very weak relation $\left(\mathrm{r}=0.096^{*}\right)$ between grain weight/ear and ear height was also noticed suggesting taller the ear height lower the grain yield/ear and vice versa. The findings of the study support that plant height and ear height were weakly related with other ear traits; nevertheless, these were highly related to grain weight/per plant. To cope with stalk lodging problem and to attain higher grain yield these varieties are equally potential and recommended to grow under Dukuchhap conditions.
\end{abstract}

Key words: Hybrid, maize, OPV, yield attributes

\section{INTRODUCTION}

Dukuchhap, an outreach research (OR) site of Khumaltar complex of Nepal Agricultural Research Council (NARC), is a village development committee (VDC) which is situated at an elevation of about $1100-1500 \mathrm{~m}$ in Lalitpur district. It is about $15 \mathrm{~km}$ away from Khumaltar, which represents sloppy land, rainfed upland, rainfed lowland and limited irrigated lowland conditions. The topography of the site varies from gentle to steep slope of hillock, flat land in the river basin, and unbounded terracing in the rainfed uplands. 
Maize is one of the important staple crops in Dukuchhap and stalk lodging is a serious limitation in local variety. To cope up this problem, farmers are shifted to hybrid maize cultivation which is high inputs demanding (fertilizer, plant protection, improved husbandry practices) and incurred high cost of hybrid seed. Aside from this, there is no guarantee of getting hybrid seed of adopted hybrid in the region because seed suppliers keep on changing such hybrids on the basis of their availability from neighboring India. The irony is that OPVs which are as good as those of hybrids are not tested and popularized in these domains. Therefore, with a view to compare most promising OPV with hybrid in the area field trials were conducted in Dukuchhap to demonstrate farmers how OPV and hybrid perform in an environment where these varieties are grown under farmers' managed conditions because it has often been perceived that OPVs cannot perform as those of hybrids.

\section{MATERIALS AND METHODS}

Field experiments were carried out at Dukuchhap, Lalitpur, $1300 \mathrm{~m}$ in normal maize season (MaySeptember) of 2006 and 2007. The experiments were conducted in randomized complete design that consisted row combination between Gaurab hybrid and Deuti, an OPV. Seed of these varieties was obtained from National Maize Research Program (NMRP), Rampur. The row combinations between hybrid and OPV were as follows: $50 \%$ hybrid $+50 \%$ OPV, $75 \%$ hybrid $+25 \%$ OPV and $25 \%$ hybrid $+75 \%$ OPV plus pure stands of hybrid and OPV. They were replicated four times in the field of two farmers.

In 2006, experiment was planted on May 1 in Kadar Thapa's field with two replications and on May 3 in Bharat Bahadur Neupane's field with two replications. In 2007, experiment was planted on May 1 in Kedar Thapa's field with four replications. In both years, at the time of planting, basal dose of $\mathrm{N}, \mathrm{P}_{2} \mathrm{O}_{5}$ and $\mathrm{K}_{2} \mathrm{O}$ was given at 50:50:60 $\mathrm{kg} \mathrm{ha}^{-1}$ from diammonium phosphate (DAP) and muriate of potash (MoP). At knee high stage, $\mathrm{N}$ at $25 \mathrm{kgha}^{-1}$ was top dressed from urea. A spacing of $75 \mathrm{~cm}$ and $25 \mathrm{~cm}$ for row and plant was maintained. All other husbandry practices were performed by farmers as practiced in the locality. A gross plot size of six rows of $3 \mathrm{~m}$ long ie $13.5 \mathrm{~m}^{2}$ per plot was maintained. For field weight recording, four innermost rows per plot were harvested. Ear attributes such as ear length, ear fill, ear weight and ear circumference were taken. Grain yield was adjusted to $15 \%$ moisture content and $80 \%$ of the field weight as shelling recovery. Grain yield was converted into hectare basis for analysis. Statistical analysis of data was done with IRRI Stat software packages version 4.5. Grain yield was calculated as follows:

Grain yield $\left(\mathrm{kgha}^{-1}\right)$ at $15 \%$ moisture content $(\mathrm{MC})=$ Field weight $(\mathrm{kg}) * 10000 *(100-\mathrm{MC}) * 0.8 / \mathrm{Net}$ harvested area*85

\section{RESULTS AND DISCUSSION}

Combined analysis of data for grain yield and yield components over the years between hybrid and OPV revealed insignificant results (Table 1). Hybrid Gaurab and OPV Deuti were found comparable for grain yield and yield attributes. However, overall performance of these attributes remained higher in 2007 than that in 2006 except for ear weight which was found higher in 2006 than in 2007. 
Table 1. Interaction effect between row combinations over years for grain yield and yield attributes of (Gaurab) and OPV (Deuti) maize tested during 2006-2007 full season under farmers' field conditions, Dukuchhap, Lalitpur

\begin{tabular}{|c|c|c|c|c|c|c|c|c|c|c|c|c|c|c|}
\hline \multirow[t]{2}{*}{ Treatment } & \multicolumn{2}{|c|}{$\begin{array}{c}\text { Plant height, } \\
\mathrm{cm}\end{array}$} & \multicolumn{2}{|c|}{ Ear height, $\mathrm{cm}$} & \multicolumn{2}{|c|}{ Ear length, $\mathrm{cm}$} & \multicolumn{2}{|c|}{ Ear fill, $\mathrm{cm}$} & \multicolumn{2}{|c|}{$\begin{array}{l}\text { Ear circum- } \\
\text { ference, } \mathrm{cm}\end{array}$} & \multicolumn{2}{|c|}{ Ear weight, $\mathrm{g}$} & \multicolumn{2}{|c|}{$\begin{array}{c}\text { Grain yield, kg } \\
\text { ha }^{-1}\end{array}$} \\
\hline & 2006 & 2007 & 2006 & 2007 & 2006 & 2007 & 2006 & 2007 & 2006 & 2007 & 2006 & 2007 & 2006 & 2007 \\
\hline $\begin{array}{l}\text { Pure stand of } \\
\text { hybrid }\end{array}$ & 235 & 254 & 110 & 132 & 21 & 20 & 18 & 18 & 15 & 16 & 213 & 181 & 4581 & 4740 \\
\hline $\begin{array}{l}\text { Pure stand of } \\
\text { OPV }\end{array}$ & 231 & 251 & 114 & 127 & 21 & 21 & 19 & 19 & 16 & 16 & 213 & 188 & 5059 & 5399 \\
\hline $\begin{array}{l}3 \text { rows hybrid }+ \\
3 \text { rows OPV }\end{array}$ & 231 & 279 & 115 & 132 & 20 & 21 & 18 & 19 & 16 & 16 & 229 & 209 & 4974 & 4905 \\
\hline $\begin{array}{l}4 \text { rows hybrid }+2 \\
\text { rows } \mathrm{OPV}\end{array}$ & 227 & 254 & 107 & 123 & 20 & 21 & 18 & 18 & 16 & 16 & 225 & 194 & 4785 & 4776 \\
\hline $\begin{array}{l}2 \text { rows hybrid }+4 \\
\text { rows OPV }\end{array}$ & 230 & 259 & 110 & 135 & 20 & 20 & 19 & 17 & 16 & 16 & 221 & 183 & 5123 & 4959 \\
\hline Grand mean & 231 & 260 & 112 & 133 & 20 & 21 & 19 & 19 & 16 & 16 & 221 & 191 & 4904 & 4956 \\
\hline $\begin{array}{l}\text { F Probability } \\
4 \text { DF }\end{array}$ & 0.376 & & 0.749 & & 0.743 & & 0.763 & & 0.218 & & 0.956 & & 0.917 & \\
\hline $\begin{array}{l}\operatorname{LSD}(\mathrm{P}<0.05) \\
12 \mathrm{DF}\end{array}$ & 24.3 & & 18.9 & & 1.8 & & 2.4 & & 0.48 & & 37.3 & & 911 & \\
\hline
\end{tabular}

Numerically average grain yield performance of pure stand of hybrid in both years was inferior $(4581-4740 \mathrm{~kg} / \mathrm{ha})$ to other treatment combinations including pure stand of OPV. This explains that OPV can compete or even be superior to hybrid at Dukuchhap conditions for obtaining increased grain yield. In other words, it can be inferred that statistically Gaurab hybrid and Deuti OPV are comparable for grain yield and yield related attributes and they are agronomically and physiologically similar in maturity, plant height and yield attributes. It is therefore advised to farmers that composite variety of maize is superior to hybrid because hybrid in general demand increased level of inputs such as fertilizer, yearly replacement of seed which is many times expensive than that of OPV, plant protection and improved husbandry practices.

A two-tailed Pearson Correlation Coefficient between agronomic traits and ear traits of Gaurab and Deuti indicated that there was a positive relation among these traits (Table 2). However, a positive and highly significant $\left(\mathrm{r}=0.766^{* *}\right)$ relation between ear fill and ear length was observed while a very weak relation $\left(r=0.096^{*}\right)$ between ear height and grain weight/ear was also noticed in the study. This suggests that taller the ear height lower the grain yield/ear. This could be one of the reasons why farmers are reporting stalk lodging in local varieties. There was a positive and highly correlated relationship among ear fill, ear length and ear circumference with grain weight/ear. The results also indicate that plant height and ear height were weakly related to other ear traits which were highly related to grain weight per ear, the important yield attribute.

Table 2. Combined over years bivariate relationship among individual ear traits and agronomic traits between hybrid (Gaurab) and OPV (Deuti) maize as affected by mixed cultures during 20062007 at Dukuchhap, Lalitpur $(n=440)$

\begin{tabular}{|c|c|c|c|c|c|}
\hline Attribute & $\begin{array}{c}\text { Plant } \\
\text { height, } \mathrm{cm}\end{array}$ & $\begin{array}{l}\text { Ear height, } \\
\mathrm{cm}\end{array}$ & $\begin{array}{c}\text { Ear } \\
\text { length, } \mathrm{cm}\end{array}$ & Ear fill & $\begin{array}{c}\text { Ear } \\
\text { circumference }\end{array}$ \\
\hline \multicolumn{6}{|l|}{ Plant height, $\mathrm{cm}$} \\
\hline Ear height, cm & $0.570(* *)$ & & & & \\
\hline Ear length, cm & $0.222(* *)$ & $0.163(* *)$ & & & \\
\hline Ear fill & $0.181(* *)$ & $0.185(* *)$ & $0.766(* *)$ & & \\
\hline Ear circumference & $0.141(* *)$ & $0.182(* *)$ & $0.308(* *)$ & $0.278(* *)$ & \\
\hline Grain weight/ear & $0.104(*)$ & $0.096(*)$ & $0.592(* *)$ & $0.645(* *)$ & $0.538(* *)$ \\
\hline
\end{tabular}


Farmers' perception for Deuti variety in the locality was found positive with respect to its taste as green cobs and lodging resistant. This variety is suited for maize-rapeseed pattern as its maturity is comparable with prevailing local variety.

In this study, there was no significant difference between varied row combinations between hybrid and OPV. However, there are studies which suggest beneficial effects of varieties mixing for many crops. Studies done by Hoekstra et al (1985a) and Midmore and Alcazar (1991) showed that varietal mixture in maize gave higher yield than their pure stands. In mixed cultivar cultures, each cultivar tends to express their competitive ability, which may result in high yields (Hoekstra et al 1985b).

\section{CONCLUSION}

On the basis of two years result of the study at Dukuchhap it is recommended that maize hybrid Gaurab and OPV Deuti are comparable for grain yield and yield components. To cope up with stalk lodging problem and to attain higher grain yield these varieties are equally potential. There is no need of growing hybrid for increased grain yield as OPV cv Deuti and similar varieties can compete with hybrid Gaurab. OPV Deuti was equally comparable with local white for maturity that gives a plus point for this variety to fit in the prevailing cropping pattern of maize-rapeseed at Dukuchhap and similar domains in the Katmandu valley.

\section{ACKNOWLEDGEMENTS}

The author expresses his gratitude to the collaborating farmers who were very positive and helpful for supporting to conduct on-farm experiments in their filed with their whole hearted support.

\section{REFERENCES}

Hoekstra GJ, LW Kannenberg and BR Christie. 1985a. Grain yield comparison of pure stands and equal proportion mixtures for seven hybrids of maize. Can. J. Plant Sci. 65:471-479.

Hoekstra GJ, LW Kannenberg and BR Christie. 1985b. Grain yield comparison of pure stands and mixtures of different proportions for two hybrids of maize. Can. J. Plant Sci. 65:481-485.

Midmore DJ and J Alcazar. 1991. Mixed planting of potato cultivars: Growth yield and leaf miner damage in the cool tropics. Exp. Agric. 1991. 305-318. 